\title{
A test of associative generalization of the conditioned eyelid response*
}

\author{
LOUISE C. PERRY, University of Wisconsin, Madison, Wis. 53706 \\ PETER A. ORNSTEIN, Princeton University, Princeton, N.J. 08540 \\ and \\ DAVID A. GRANT, University of Wisconsin, Madison, Wis. 53706
}

Associative generalization of the conditioned eyelid response was tested following a series of 45 classical conditioning trials to the CS word, TABLE. During the 15 generalization (extinction) trials, five groups of $20 \mathrm{Ss}$ each were presented with either the CS word itself or with one of four other words associatively related in various degrees to the CS. No generalization gradient was evident on the first test trial. Trend analyses of percent responses during each of the three five-trial blocks of generalization revealed a linear gradient of associative generalization during the second trial block, but only for those Ss showing the voluntary-form eyelid CR.

While the occurrence of generalization to semantically related stimuli is a somewhat elusive, but fairly well-documented, phenomenon (e.g., Razran, 1961), the occurrence of smooth monotonic gradients of semantic generalization is an issue still open to question. With respect to instrumental conditioning procedures, there now appears to be good evidence for such gradients (e.g., Cramer, 1970). In classical conditioning, however, the findings have been variable. For example, defining degree of associative relatedness in terms of the Bousfield (1961) index, Cole \& Williams (1966) found associative generalization of the GSR; i.e., more response to test words associatively related to the $\mathrm{CS}$ than to neutral words, but the generalization gradient was not monotonic in form.

The lack of clear evidence of generalization gradients in the classical conditioning work may be due, in part, to methodological problems peculiar to the GSR (Feather, 1965). In view of this, the eyelid response would seem to provide an excellent alternative. It has the advantages of being a shorter latency response and one for which an extensive body of experimental data is already available; further, the possibility of separating out voluntary (V) from classical (C) form eyelid CRs affords an opportunity to investigate the relation of response topography to semantic generalization (Hartman, 1963). Despite all these advantages, however, surprisingly little semantic generalization work has as, yet employed the eyelid CR as the dependent variable. The purpose of

*This work was supported in part by Public Health Service Grant MH06792 to David A. Grant. Additional support was provided by PHS predoctoral fellowships from the National Institute of Mental from the National Institute of Peter A. Ornstein. the present study, therefore, was to determine if a monotonic gradient of associative generalization can, in fact, be demonstrated using the eyelid $C R$ as the dependent measure. Further, in contrast to most semantic generalization work, the present study employed a between-S design in order to provide a test of semantic generalization which would completely preclude generalization stimulus word-order effects.

\section{METHOD}

All Ss received $\mathbf{4 5}$ initial classical conditioning trials in which the CS was the visually presented word, TABLE. The acquisition series was immediately followed by 15 extinction trials. The independent variable was the stimulus word presented during these 15 extinction trials. For five independent groups of $20 \mathrm{Ss}$ each, the extinction stimulus was either the CS word, TABLE, itself (Group 1) or one of four other words associatively related in various degrees to the CS (Groups 2-5).

The stimuli were all common five-letter singular nouns selected from the Palermo-Jenkins (1964) word association norms for 500 women college students. An attempt was made to sample as wide a range of associative relatedness as possible, with associative relatedness defined in terms of the Bousfield (1961) index of generalization. The five words chosen were TABLE (CS), CHAIR, BREAD, FRUIT, and OCEAN (Groups 1-5, respectively), with respective generalization index values of 1.00 $.548, .162, .074$, and .008 .

The equipment was similar to that used by Cerekwicki, Grant, \& Porter (1968). The $\mathrm{S}$ sat in a soundproof chamber facing a ground-glass screen on which the stimuli were projected from the rear. An adjustable headset worn by the $S$ carried a microtorque potentiometer and the air jet that delivered the UCS. The shaft of the potentiometer was taped to the right eyelid. The duration of the CS and generalization stimuli was $1,200 \mathrm{msec}$ and the UCS, a puff of nitrogen to the cornea of the right eye, followed $1,000 \mathrm{msec}$ after CS onset on the $\mathbf{4 5}$ training trials. The intensity of the UCS was 2.0 psi at the cornea, and its duration was 200 msec. Intertrial intervals ranged from 15 to $25 \mathrm{sec}$, with a mean of $20 \mathrm{sec}$.

The Ss were 100 women students at the University of Wisconsin. Half of the Ss in each group were paid, while the other half were volunteers given class credit for participation in the experiment. Two Es each tested half the Ss in each group. Standard neutral instructions were given to all $\mathrm{Ss}$ prior to the conditioning trials, i.e., Ss were not to aid or inhibit their natural eyelid responses.

\section{RESULTS}

For both acquisition and generalization trials, all eyelid closures at least $1 \mathrm{~mm}$ in magnitude which had latencies from 200 to $1,000 \mathrm{msec}$ after CS (or test stimulus) onset were considered CRs. The Ss were divided into voluntary-form responders (Vs) and conditioners (Cs) on the basis of the $\mathrm{CR}$ form shown during acquisition, using the objective criterion proposed by Hartman \& Ross (1961). The number of $\mathrm{Vs}$ in Groups 1.5 was six, six, six, seven, and eight; the remainder of the $20 \mathrm{Ss}$ in each group were Cs.

A three-way mixed analysis of variance on percent $\mathrm{CR}$ s during initial acquisition (Groups by VC by Five-Trial Blocks) indicated that the five experimental groups did not differ significantly in original conditioning performance. The Vs gave more CRs than did Cs throughout the acquisition trials, $\quad F(1,90)=6.41, \quad p<.05, \quad$ a commonly obtained finding (e.g., Cerekwicki et al, 1968). There was also a significant trial-blocks effect, $F(8,720)=8.07, p<.01$, indicating that conditioning did occur during the initial training phase.

Anticipatory eyelid closures on the first generalization trial provide the only measure of associative generalization which is not influenced by extinction ef fects. Percent response on this trial is plotted in Fig. 1 (filled squares) as a function of degree of associative relatedness between the test stimulus and the CS, with the data for Vs presented in Panel $A$ and the data for $C s$ in Panel $B$. There is no indication of a monotonic gradient of generalized responding on Trial 1 for either Vs or Cs. Kendall's $r$, computed separately for $\mathrm{Vs}$ and $\mathrm{Cs}$, indicated that there was no significant relationship between degree of associative relatedness and the probability of a $C R$ on the first 


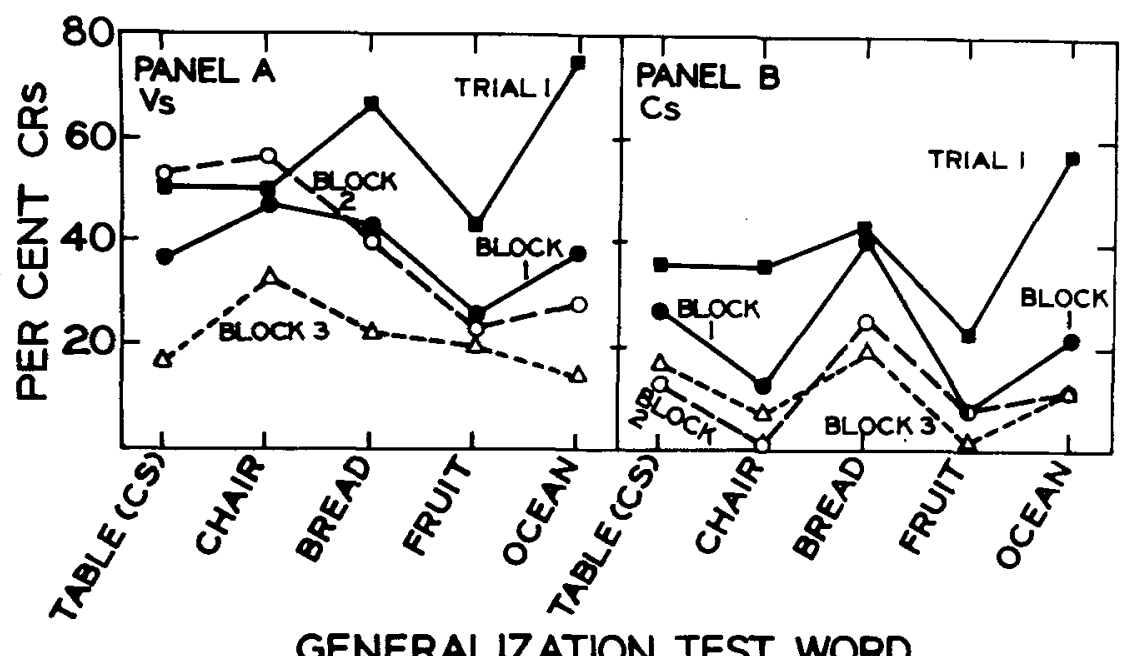

GENERALIZATION TEST WORD

(IN ORDER OF DECREASING RELATEDNESS TO THE CS)

Fig. 1. Percentage CRs during the first test trial and the three five-trial blocks of the generalization (extinction) test, as a function of degree of associative relatedness between the test word and the CS (TABLE). Panel A presents the data for voluntary-form responders, while Panel $B$ presents the data for conditioners.

generalization trial for either Vs or Cs $(\tau=-.49$ for both $\mathrm{Vs}$ and Cs, $\mathrm{p}=.325$ ).

Percent response curves for each of the three five-trial blocks of generalization are also plotted in Fig. 1 as a function of degree of associative relatedness between the test word and the CS. It may be seen that the responding of Cs (Panel $B$ ) is generally lower than that of Vs (Panel A) and does not appear to be systematically related to degree of associative relatedness at any time during the extinction phase. The performance of Vs, however, does give some suggestion of a decremental generalization gradient, most clearly evident during the second trial block (open circle curve in Panel A). In trend analyses ${ }^{1}$ performed on each of the three trial blocks of extinction, response topography produced significant effects in both Block 1 , $\mathrm{F}(1,90)=6.08, \mathrm{p}<.05$, and Block 2, $F(1,90)=21.06, \quad p<.01, \quad$ reflecting the generally higher response level of Vs than of Cs during the first 10 of the 15 extinction trials. The Block 1 analysis also revealed a quartic associative relatedness trend, $F(1,90)=4.69, p<.05$, due to the high level of response to the intermediate and least related test words (BREAD and OCEAN) which was shown by both Vs and Cs on the early test trials. Only in Block 2 was there any suggestion of possible monotonicity in the generalization gradient. The linear component of the trends for Vs and Cs differed significantly during the second trial block, $F(1,90)=4.23, p<.05$, and subsequent separate trend analyses on $\mathrm{V}$ - and $\mathrm{C}$-form responders confirmed that Vs showed a statistically significant linearity in the generalization gradient during Block 2, $F(1,90)=7.74, p<.05$, while there were no significant trends for Cs.

\section{DISCUSSION}

It had been thought that response on the first test trial would provide a relatively "pure" test of generalization, since no other tests preceded it and since no extinction had yet had an opportunity to occur (the $S$ had not yet experienced omission of the UCS). The lack of any consistent relationship between degree of associative relatedness and Trial 1 responding was, therefore, puzzling. Although no obvious explanation for these results is available, one factor which may be involved is an interaction of associative generalization with the occurrence of an orienting blink response (OR) to novel stimuli (see Razran, 1961). The most novel stimulus in terms of its associative relationship to the CS was the test word, OCEAN. The occurrence of the greatest amount of responding to this word, therefore, suggests that the OR may be dominant on the initial test trial. A complex interaction between associative generalization and the OR may also be partially responsible for the quartic associative relatedness trend during the first generalization trial block, a finding which seems inexplicable at the present time.

The only evidence of systematic associative generalization effects in the present study was the suggestion of a linear generalization gradient for those $\mathrm{Ss}$ showing the $\mathrm{V}$ response topography, but not for Cs, during the second trial block of extinction. This indication, that only the $V$-form responders were sensitive to the associative relatedness variable, is in agreement with other data from the Wisconsin laboratory (e.g., Cerekwicki et al, 1968), which show that Vs tend to be more influenced by verbal relatedness of the CSs employed than are Cs. The significant interaction of the associative relatedness trend with response topography demonstrates the importance of categorizing $S$ s on the basis of their response form when the eyelid conditioning procedure is used. Without such a classification, the indication of a linear generalization gradient during the intermediate trials of extinction would have been largely obscured in the present experiment.

In general, however, the present study offers little evidence to support the notion of a monotonic gradient of associative generalization. Nevertheless, the methodological advantages of the eyelid $C R$ and the encouraging results obtained when Ss are separated in terms of response topography suggest the potential value of the eyelid measure in the study of semantic generalization.

\section{REFERENCES}

BOUSFIELD, W. A. The problem of meaning in verbal learning. In C. N. Cofer (Ed.), Verbal learning and verbal behavior. New York: McGraw-Hill, 1961. Pp. 81-91.

CEREKWICKI, L. E., GRANT, D. A., \& PORTER, E. C. The effect of number of relatedness of verbal discriminanda upon differential eyelid conditioning. Journal of Verbal Learning \& Verbal Behavior, $1968,7,847-853$.

COLE, S. \& WILLIAMS, R. L. Semantic generalization as a function of associative value of stimuli. Psychonomic Science, $1966,6,173-174$.

CRAMER. P. Semantic generalization: Demonstration of an associative gradient. Journal of Experimental Psychology, 1970, 84, 164-172.

FEATHER, B. W. Semantic generalization of classically conditioned responses: A review. Psychological Bulletin, 1965, 63, 425-441.

HARTMAN, T. F. Semantic transfer of the differential conditioned eyelid response from words to objects. Journal of Experimental Psychology, 1963, 65, 194-200.

HARTMAN, T. F., \& ROSS, L, E, An alternative criterion for the elimination of "voluntary" response in eyelid conditioning. Journal of Experimental Psychology, 1961, 61, 334-338.

PALERMO, D. A., \& JENKINS, J. J. Word association norms. Minneapolis: University of Minnesota Press, 1964.

RAZRAN, G. The observable and the inferable conscious in current Soviet psychophysiology: Interoceptive conditioning, semantic conditioning, and the orienting response. Psychological Review, 1961, 68, 81-147. NOTE

1. Because the scale properties of the Bousfield generalization inde $x$ are not clear and because the basic question of scaling semantic distance is a very complex problem whose solution the authors did not wish to attempt at this time, the exact Bousfield scale values of the test stimuli were not used in the trend analyses, and instead. equal-interval trend analyses were arbitrarily carried out to ascertain approximately the form of the generalization gradients. 